\title{
Selective hydrogenation of D-glucose to D-sorbitol over Ru/ZSM-5 catalysts
}

\author{
Xingcui Guo a, Xicheng Wang a , Jing Guan a, Xiufang Chen ${ }^{a}$, Zhangfeng Qin ${ }^{b}$, Xindong Mu ${ }^{a}$,*, Mo Xian ${ }^{a}$ \\ a Key Laboratory of Bio-based Materials, Qingdao Institute of Bioenergy and Bioprocess Technology, Chinese Academy of Sciences, Qingdao 266101, \\ Shandong, China \\ b State Key Laboratory of Coal Conversion, Institute of Coal Chemistry, Chinese Academy of Sciences, Taiyuan 030001, Shanxi, China
}

\section{A R T I C L E I N F O}

Article history:

Received 20 January 2014

Accepted 13 March 2014

Published 20 May 2014

\section{Keywords:}

Hydrogenation

D-glucose

D-sorbitol

Ruthenium

ZSM-5

\begin{abstract}
A B S T R A C T
Ru particles were introduced into the zeolite ZSM-5 (MFI) by either a conventional impregnation method or a one-step template-free process. The resultant materials were characterized by X-ray diffraction, $\mathrm{N}_{2}$ adsorption-desorption, scanning electron microscopy, transmission electron microscopy, $\mathrm{NH}_{3}$ and $\mathrm{CO}_{2}$ temperature-programmed desorption. The results indicated that the $\mathrm{Ru}$ species in ZSM- 5 catalysts prepared via the latter approach (designated as Ru/ZSM-5-TF) were highly dispersed in the ZSM-5 framework structure and this material exhibited high catalytic performance during the hydrogenation of D-glucose to D-sorbitol. The conversion of D-glucose was as high as $99.6 \%$ with D-sorbitol selectivity reaching $99.2 \%$, exceeding the performance of Ru/ZSM- 5 catalysts prepared by the conventional impregnation method with microporous or desilicated ZSM-5 supports. More importantly, this catalyst showed high stability against leaching and poisoning and could be reused several times. The extensive dispersion of the Ru species, strong interaction between the Ru species and the ZSM-5, and the suitable surface acidity-basicity balance of the $\mathrm{Ru} / \mathrm{ZSM}-5$-TF were all critical factors leading to excellent catalytic behavior and stability.
\end{abstract}

(C) 2014, Dalian Institute of Chemical Physics, Chinese Academy of Sciences. Published by Elsevier B.V. All rights reserved.

\section{Introduction}

Approximately 700,000 tonnes of D-sorbitol are synthesized each year worldwide by the catalytic hydrogenation of D-glucose, which represents an inexpensive, abundant feedstock obtainable from renewable resources such as starchcontaining crops or cellulose [1-4]. D-sorbitol has many applications in the food, pharmaceutical, cosmetic and paper industries, and it can also be used as a building block in the synthesis of various fine chemicals, including vitamin C [5-7].

Most of the industrial processes for the synthesis of this compound are based on the batch-wise hydrogenation of
D-glucose to D-sorbitol over Raney Ni catalysts, promoted by various transition metals [8]. Although Raney Ni has several advantages, such as low cost, excellent setting and high activity, the risk of leaching of the $\mathrm{Ni}$ or of the metal promoter reduces the economic benefits of the process [9]. The more stable supported Ru catalysts have demonstrated good activity and excellent selectivity during the hydrogenation of sugars, but have the drawback of high cost. To reduce this cost, Ru nanoparticles have been dispersed on different solid supports, including silica $[10,11]$, multi-wall carbon nanotubes [12], activated carbons $[13,14]$, alumina oxides [15-17], and some synthetic materials such as synthetic zeolites [18], which have also been studied

\footnotetext{
* Corresponding author. Tel: +86-532-80662723; Fax:+86-532-80662724; E-mail: muxd@qibebt.ac.cn

This work was supported by the National Natural Science Foundation of China (21273260, 21303238, and 21201174), the Shandong Provincial Natural Science Foundation for Distinguished Young Scholar, China (JQ201305), and the Foundation of State Key Laboratory of Coal Conversion (J13-14-603).

DOI: 10.1016/S1872-2067(14)60077-2 | http://www.sciencedirect.com/science/journal/18722067 | Chin. J. Catal., Vol. 35, No. 5, May 2014
} 
for the dehydration of D-glucose. However, these catalysts are typically prepared using conventional methods such as impregnation followed by $\mathrm{H}_{2}$ reduction. These supported catalysts also suffer from the disadvantage of rapid deactivation, likely resulting from the relatively weak interaction between the metal and the support as well as the limited diffusion of reactants/products within the support materials [19], leading to aggregation/sintering and leaching of Ru particles during use [20]. In addition, there is no way to precisely control the size and location of metal particles on the solid supports through the conventional synthetic approaches [21].

ZSM-5 zeolites with appropriate acidity and good shape-selectivity are widely used as supports in hydrogenation reactions [22]. Recently, more direct, template-free syntheses of Ru-containing ZSM-5 composites have been described [23-25], which provide control over both the texture and $\mathrm{Si} / \mathrm{Al}$ ratio without any requirement for additives. $\mathrm{RuO}_{2}$ clusters of uniform size (ca. $1 \mathrm{~nm}$ ) have been deposited predominantly in MFI (ZSM-5) channels during hydrothermal synthesis and subsequently exhibit high reactivity for 1-hexene hydrogenation after reduction [26]. More importantly, encapsulation of metal or oxide clusters within zeolites can protect such clusters against sintering and also reduce their contact with toxic impurities, while concurrently allowing the active sites to select reactants and transition states on the basis of molecular size [25].

To date, the fabrication of highly dispersed metal nanoparticles within molecular sieve materials with tunable pore-sizes, and their subsequent use as catalysts for the hydrogenation of sugar alcohols, has not been reported in the literature. In the work reported herein, uniform Ru nanoparticles with an average diameter of less than $1 \mathrm{~nm}$ and encapsulated in ZSM-5 were prepared by a one-step, template-free method using $\mathrm{RuCl}_{3}$ as the Ru precursor. The preparation method was simple and fast and allowed the prepared Ru clusters to be finely dispersed in the ZSM-5 support. We report herein that the materials prepared in this manner resulted in significant improvements in the D-sorbitol yields during the hydrogenation of D-glucose.

\section{Experimental}

\subsection{Materials}

$\mathrm{Ru} / \mathrm{C}$ (5 wt\%) was purchased from Aladdin Reagent Co., Ltd., while $\mathrm{RuCl}_{3} \cdot x \mathrm{H}_{2} \mathrm{O}$ (AR, 37.5 wt\% Ru), $\mathrm{NaOH}$ (AR, 96 wt\%), $\mathrm{NaAlO}_{2}$ (54 wt $\% \mathrm{Al}_{2} \mathrm{O}_{3}, 41$ wt\% $\mathrm{Na}_{2} \mathrm{O}, 5$ wt $\% \mathrm{H}_{2} \mathrm{O}$ ), D-glucose and D-sorbitol were purchased from Sinopharm Chemical Reagent Co., Ltd. (Shanghai, China). The colloidal silica sol Ludox HS-40 (40 wt\% in water, average particle size $12 \mathrm{~nm}$ ) was purchased from Aldrich. Commercially available ZSM-5 (Si/Al = 38) was acquired from the Catalyst Plant of Nankai University and was dried at $120^{\circ} \mathrm{C}$ for $24 \mathrm{~h}$ before use.

\subsection{Catalyst preparation}

The incorporation of the $\mathrm{Ru}$ was realized by two different methods: an impregnation process and an in situ one-step process. In the first method, MFI-type zeolites were synthesized by a modified version of Weitkamp's method [24], with the molar composition $n \mathrm{RuO}_{2}: n \mathrm{SiO}_{2}: n \mathrm{Al}_{2} \mathrm{O}_{3}: n \mathrm{Na}_{2} \mathrm{O}: n \mathrm{H}_{2} \mathrm{O}=0.65 \sim 2.81: 38$ : 1:11.5:2800. A solution of $2.35 \mathrm{~g} \mathrm{NaOH}$ and $0.7112 \mathrm{~g}$ sodium aluminate in $90 \mathrm{~g} \mathrm{H}_{2} \mathrm{O}$ was added to $21.71 \mathrm{~g}$ Ludox HS-40 with stirring, after which $25 \mathrm{~mL}$ of a solution containing the desired amount of $\mathrm{RuCl}_{3} \times \mathrm{H}_{2} \mathrm{O}$ was added to the initial mixture. This combined mixture was then stirred at $50{ }^{\circ} \mathrm{C}$ for $3 \mathrm{~h}$ followed by crystallization in a rotating stainless-steel autoclave $\left(100 \mathrm{~cm}^{3}\right)$ for $4 \mathrm{~d}$ at $160{ }^{\circ} \mathrm{C}$. Upon completion, the template-free zeolite $\mathrm{Ru} / \mathrm{ZSM}-5-\mathrm{TF}$ was obtained.

ZSM-5 with framework $\mathrm{Si} / \mathrm{Al}$ ratios in the range of $25-50$ has been shown to be an eligible structure for the introduction of mesoporosity via desilication. In this work, alkali-treated ZSM-5 samples ( $\mathrm{Si} / \mathrm{Al}=38$ ), denoted as ZSM-5-AT, were fabricated by immersing the zeolite in a $0.3 \mathrm{~mol} / \mathrm{L} \mathrm{NaOH}$ solution at $65{ }^{\circ} \mathrm{C}$ for $120 \mathrm{~min}$. The treated samples were subsequently filtered, washed with distilled water, dried at $80{ }^{\circ} \mathrm{C}$, ion-exchanged with $\mathrm{NH}_{4} \mathrm{NO}_{3}$ solution $(0.1 \mathrm{~mol} / \mathrm{L})$ three times and finally calcined in static air at $550{ }^{\circ} \mathrm{C}$ for $4 \mathrm{~h}$ at a heating rate of $1{ }^{\circ} \mathrm{C} / \mathrm{min}$.

For comparison purposes, Ru/ZSM-5 catalysts were also prepared by the incipient wetness impregnation method at ambient temperature, employing an aqueous $\mathrm{RuCl}_{3}$ solution as the $\mathrm{Ru}$ precursor. The preparation procedure associated with the impregnation method involved impregnating the dry supports (commercial microporous ZSM-5 zeolites with $\mathrm{Si} / \mathrm{Al}=38$, denoted as ZSM-5-MS, and mesoporous ZSM-5 created by desilication in alkaline medium, denoted as ZSM-5-AT) with an aqueous solution of $\mathrm{RuCl}_{3}$. To achieve incipient wetness, a liquid $\left(\mathrm{RuCl}_{3} / \mathrm{H}_{2} \mathrm{O}\right.$ solution of $\left.20.1 \mathrm{mg} / \mathrm{mL}\right)$ to solid ratio of 2.0 $\mathrm{mL} / \mathrm{g}$ was used. Following impregnation and subsequent ultrasonic treatment $(600 \mathrm{~W})$ for $2 \mathrm{~h}$, the mixture was continuously stirred under ambient conditions to allow slow evaporation of water. The samples were then dried overnight at $110^{\circ} \mathrm{C}$, followed by reduction in $\mathrm{H}_{2}$ at $350{ }^{\circ} \mathrm{C}$ for $3 \mathrm{~h}$. The obtained sample was designated as Ru/ZSM-5-MS and Ru/ZSM-5-AT.

\subsection{Catalyst characterization}

The X-ray powder diffraction (XRD) patterns of catalysts were obtained with a Bruker D8 Advance X-ray diffraction instrument, using Ni-filtered $\mathrm{Cu}-K_{\alpha}$ radiation. $\mathrm{N}_{2}$ adsorption-desorption experiments were performed with a Micromeritics ASAP 2020 surface area and porosity analyzer and ICP analyses were carried out on a Thermo IRIS Intrepid II XSP atomic emission spectrometer to determine the chemical composition of catalysts and to examine metal leaching during reactions. $\mathrm{NH}_{3}$ temperature-programmed desorption ( $\left.\mathrm{NH}_{3}-\mathrm{TPD}\right), \mathrm{CO}_{2}$ temperature-programmed desorption ( $\mathrm{CO}_{2}$-TPD) and $\mathrm{H}_{2}$ temperature-programmed reduction $\left(\mathrm{H}_{2}-\mathrm{TPR}\right)$ data were acquired using a Micromeritics Autochem II chemisorption analyzer. Transmission electron microscopy (TEM) images were taken using a field emission H-7600 electron microscope at $120 \mathrm{kV}$, while scanning electron microscopy (SEM) analysis was conducted on a Hitachi S-4800 electron microscope working at 200 $\mathrm{kV}$. 


\subsection{Catalytic tests}

The hydrogenation of D-glucose was performed in a 100-mL stainless autoclave. Following the loading of the autoclave with $0.5 \mathrm{~g}$ of catalyst and $50 \mathrm{~mL}$ of a $25 \mathrm{wt} \%$ D-glucose solution, the reactor was purged with hydrogen four times to remove air, then operated at the desired pressure and temperature for a predefined span of time with stirring at $500 \mathrm{r} / \mathrm{min}$. The product distribution following reaction was analyzed by high-pressure liquid chromatography (HPLC) with refractive index (RI) detection (column: Aminex HPX-87C at $70{ }^{\circ} \mathrm{C}$, mobile phase: 0.006 $\mathrm{mol} / \mathrm{L}$ sulfuric acid at $0.5 \mathrm{~mL} / \mathrm{min}$ ).

\section{Results and discussion}

\subsection{Catalyst characterization}

Figure 1 presents the XRD patterns of ruthenium-containing MFI-type zeolites, including the Ru/ZSM-5-TF, Ru/ZSM-5-MS and $\mathrm{Ru} / Z S M-5-A T$ catalysts. All ZSM-5 samples showed well-resolved diffraction peaks at $2 \theta=8^{\circ}-9^{\circ}, 23^{\circ}-25^{\circ}$, and $45^{\circ}$, all of which are characteristic of the MFI-type structure [27]. In the case of the Ru/ZSM-5-TF catalyst, no reflections due to metallic $\mathrm{Ru}, \mathrm{RuO}_{x}$ or any other crystalline phases were present, indicating that the Ru species prepared by the one-step method were amorphous or had a particle size of $1 \mathrm{~nm}$ or less [28]. However, in the patterns obtained for the Ru/ZSM-5-AT and $\mathrm{Ru} / \mathrm{ZSM}-5-\mathrm{MS}$ materials, signals were observed at $2 \theta=38.3^{\circ}$ and $44.0^{\circ}$ along with an additional weak reflection at $58.3^{\circ}$.

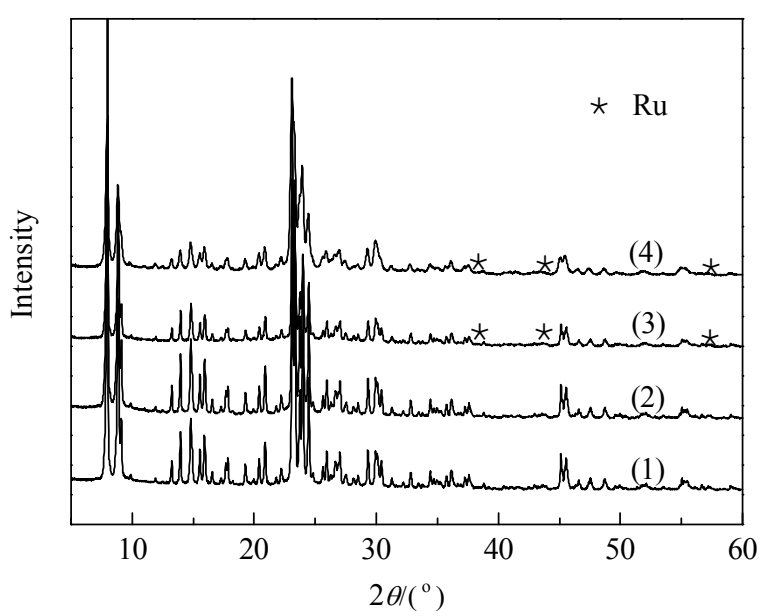

Fig. 1. XRD patterns of the ZSM-5 type zeolites. (1) ZSM-5; (2) Ru/ZSM-5-TF; (3) Ru/ZSM-5-AT; (4) Ru/ZSM-5-MS.

These reflections could be assigned to the (100), (101), and (102) diffraction planes of bulk hexagonal $\mathrm{Ru}$ metal (JCPDS-ICDD card No. 06-0663) and may be due to the presence of a few large Ru particles forming on the external surfaces of the catalysts.

The $\mathrm{N}_{2}$ adsorption data obtained for the various $\mathrm{Ru} / \mathrm{ZSM}-5$ samples are presented in Table 1 , and the $\mathrm{N}_{2}$ adsorption-desorption isotherms and pore size distribution (PSD) curves for the catalysts are shown in Fig. 2. The isotherms of $\mathrm{Ru} / \mathrm{ZSM}-5-\mathrm{TF}$ and Ru/ZSM-5-MS both exhibited very high adsorption below $p / p_{0}=0.1$, implying a large micropore volume,

Table 1

Physicochemical properties of the catalysts and their catalytic activities in D-glucose hydrogenation.

\begin{tabular}{lccccccc}
\hline Catalysts & $\mathrm{SiO}_{2} / \mathrm{Al}_{2} \mathrm{O}_{3}$ ratio $^{\mathrm{a}}$ & $S_{\mathrm{BET}}\left(\mathrm{m}^{2} / \mathrm{g}\right)^{\mathrm{b}}$ & $V_{\text {micro }}\left(\mathrm{cm}^{3} / \mathrm{g}\right)^{\mathrm{c}}$ & $V_{\text {meso }}\left(\mathrm{cm}^{3} / \mathrm{g}\right)^{\mathrm{d}}$ & $\mathrm{D}(\mathrm{nm})^{\mathrm{e}}$ & Acid $(\mathrm{mmol} / \mathrm{g})$ & Dispersion \\
\hline $\mathrm{HZSM-5}$ & 38 & 358 & 0.20 & 0.10 & 0.55 & 3.6 & - \\
$\mathrm{Ru}-Z S M-5-\mathrm{TF}$ & 38 & 383 & 0.25 & 0.13 & 0.52 & 3.1 & 0.54 \\
$\mathrm{Ru} /$ ZSM-5-MS & 38 & 339 & 0.16 & 0.07 & 0.26 & 2.1 \\
$\mathrm{Ru} /$ ZSM-5-AT & 30 & 345 & 0.08 & 0.32 & 0.66 & 3.4 & 0.46 \\
\hline
\end{tabular}

a Determined by ICP-OES.

b Surface areas were obtained by the BET method using adsorption data at $p / p_{0}=0.05-0.25$.

${ }^{c}$ Determined by the t-plot method.

${ }^{\mathrm{d}} V_{\text {meso }}=V_{\text {ads. }} / \mathrm{po}=0.995-V_{\text {micro. }}$.

e Average pore diameters were derived from the adsorption branches of the isotherms by the BJH method.
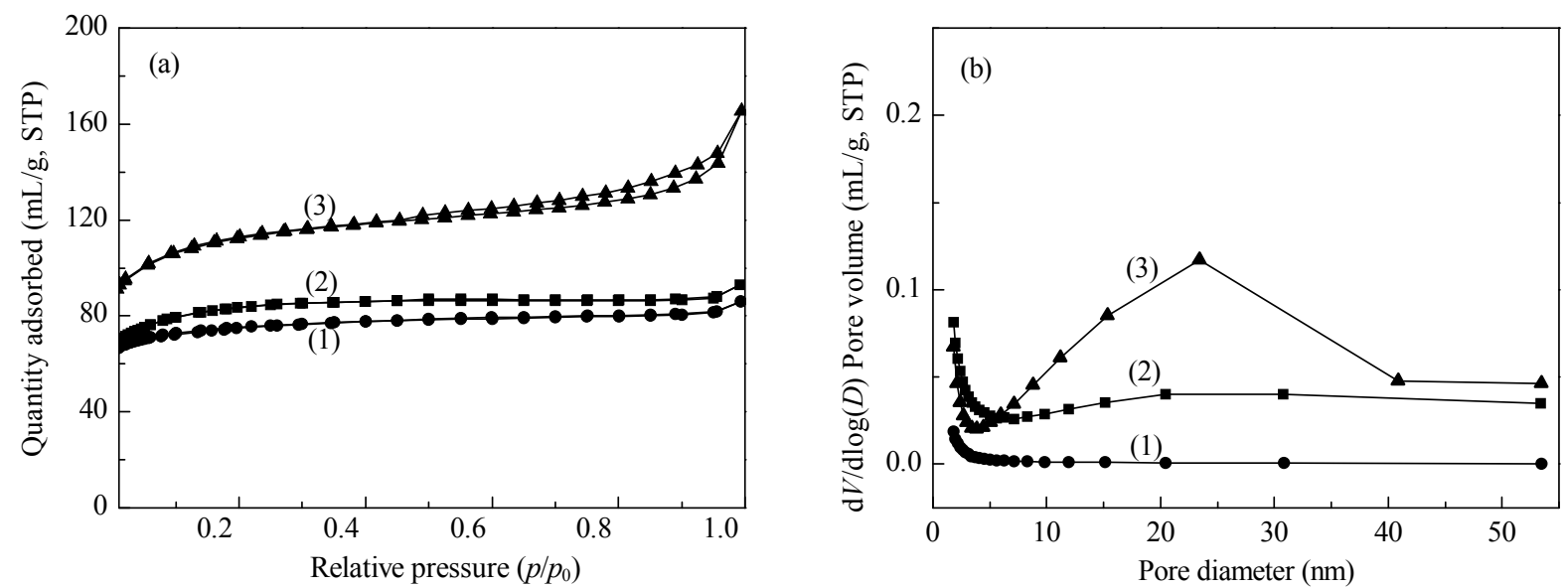

Fig. 2. $\mathrm{N}_{2}$ adsorption and desorption isotherms (a) and corresponding pore size distributions (b) for Ru/ZSM-5-MS (1), Ru/ZSM-5-TF (2), and $\mathrm{Ru} / \mathrm{ZSM}-5$-AT (3). 
and showed a type I isotherm [29,30]. The BET surface area and total pore volume of the $\mathrm{Ru} / \mathrm{ZSM}$-MS were $339 \mathrm{~m}^{2} / \mathrm{g}$ and $0.23 \mathrm{~cm}^{3} / \mathrm{g}$, respectively. Ru/ZSM-5-AT generated an isotherm representing both types I and IV behaviors, with a remarkably enhanced uptake of nitrogen at higher pressures. This suggested the presence of both micro and mesoporosity, which was supported by the t-plot results shown in Table 1 . The BET surface area and mesoporous volume for Ru/ZSM-5-AT were $345 \mathrm{~m}^{2} / \mathrm{g}$ and $0.32 \mathrm{~cm}^{3} / \mathrm{g}$, respectively, suggesting that larger mesopores were present in the desilication products, compared with $\mathrm{Ru} / \mathrm{ZSM}-5-\mathrm{TF}$. It was clear that the micropore volume ( $\left.V_{\text {micro }}\right)$ of the Ru/ZSM-5-MS catalyst was twice that of the $\mathrm{Ru} / \mathrm{ZSM}-5$-AT catalyst.

Figure 3(a) provides the $\mathrm{NH}_{3}$-TPD profiles for $\mathrm{Ru} / \mathrm{ZSM}-5$ samples. The acid amount and strength were essentially unchanged by the acid treatment, indicating that the application of different treatment methods did not affect the acidic character of the catalyst. In contrast, considerable changes were ob- served in the basicity, as measured by $\mathrm{CO}_{2}$-TPD (Fig. 3(b)). Large $\mathrm{CO}_{2}$ desorption peaks were observed for the $\mathrm{Ru} / \mathrm{ZSM}-5$-TF catalysts, while in the case of the Ru/ZSM-5-AT, the $\mathrm{CO}_{2}$ adsorption decreased in comparison with $\mathrm{Ru} / \mathrm{ZSM}-5-\mathrm{TF}$, and no peak was observed for Ru/ZSM-5-MS, indicating the presence of weak basic sites.

A rather dramatic change in the morphology of $\mathrm{Ru} / \mathrm{ZSM}-5$ was found to correlate with the use of different preparation methods. Typical SEM images of Ru/ZSM-5-TF revealed similar void spaces only in rare instances. Instead, these particles exhibited surfaces with small bumps (Fig. 4(a)). Ru particles with diameters between 0.5 and $0.9 \mathrm{~nm}$ were homogeneously distributed over the catalyst (Fig. 4(d)). In contrast, the SEM images of ZSM-5-AT shown in Fig. 4(b) show that some cracks and faults appeared on the surface of ZSM-5 particles after alkali treatment for $120 \mathrm{~min}$ in a $\mathrm{NaOH}$ solution $(0.3 \mathrm{~mol} / \mathrm{L})$. To elucidate internal changes in particle morphology, the alkali-treated ZSM-5 was examined by TEM, as shown in Fig. 4(e).
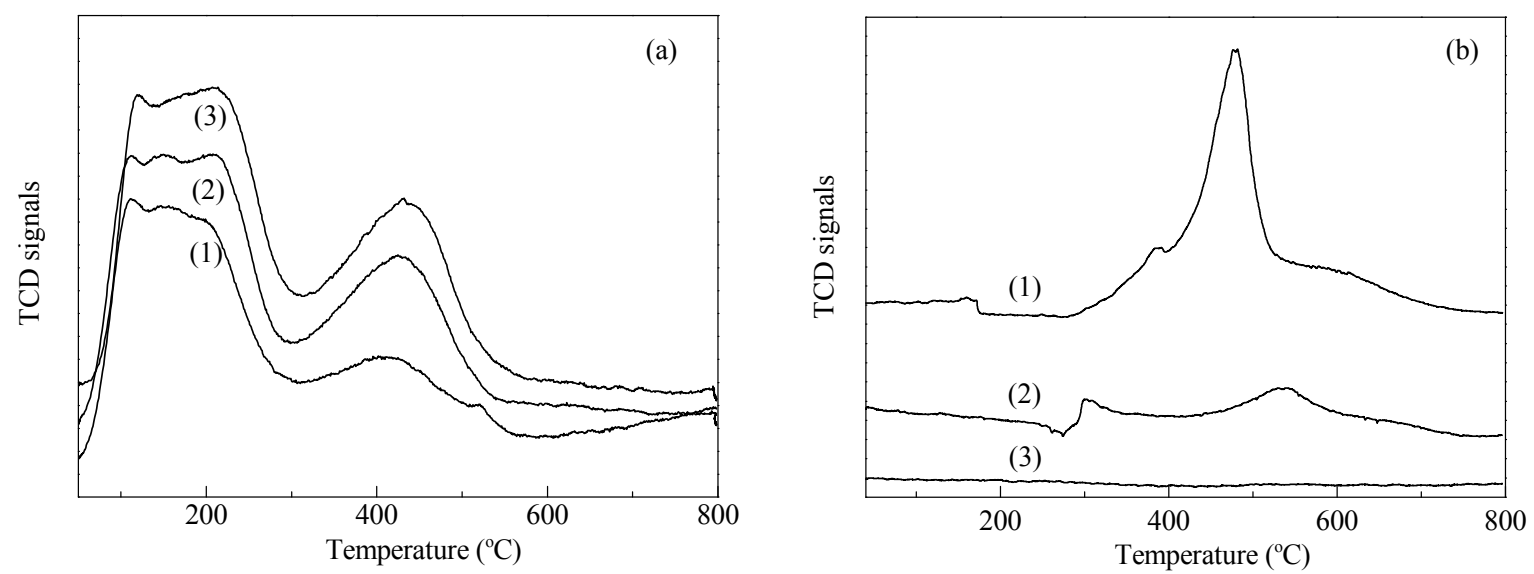

Fig. 3. $\mathrm{NH}_{3}$-TPD (a) and $\mathrm{CO}_{2}$-TPD (b) profiles of Ru-containing ZSM-5 samples prepared with different methods. (1) Ru/ZSM-5-TF; (2) Ru/ZSM-5-AT; (3) Ru/ZSM-5-MS.
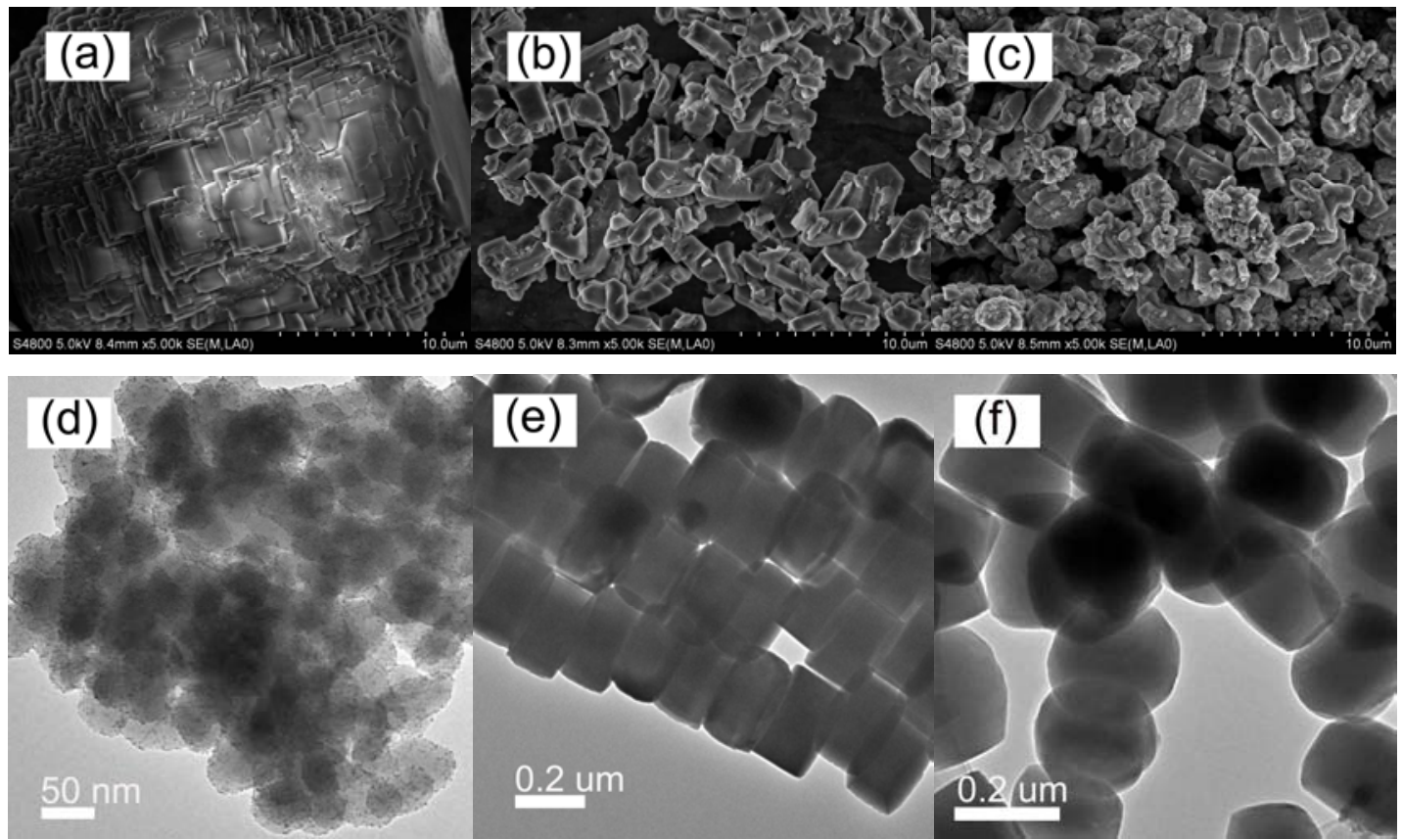

Fig. 4. SEM images (a-c) and TEM images (d-f) of the Ru-containing ZSM-5 sample. (a,d) Ru/ZSM-5-TF; (b,e) Ru/ZSM-5-AT; (c,f) Ru/ZSM-5-MS. 
Mesopores throughout the particles were clearly observed on the sample, and the edges appeared to be deformed. In the case of Ru/ZSM-5-MS, however, its TEM image (Fig. 4(f)) showed rather inhomogeneous $\mathrm{Ru}$ distribution and large particle sizes up to $3.0 \mathrm{~nm}$ in diameter. Therefore, a large fraction of the $\mathrm{Ru}$ particles must be located on the outer surfaces of the ZSM-5 crystals.

\subsection{Catalytic performances for D-glucose hydrogenation over $\mathrm{Ru} / \mathrm{ZSM}-5$ catalysts}

As discussed, catalysts based on $\mathrm{Ru}$ have potential for the hydrogenation of D-glucose, and the results obtained during the catalytic D-glucose hydrogenation using different types of $\mathrm{Ru} / \mathrm{ZSM}-5$ catalysts were studied and summarized in detail in Table 2. Almost none of the target product D-sorbitol was observed when applying the ZSM-5 at $120^{\circ} \mathrm{C}$ in the absence of $\mathrm{Ru}$. Among the catalysts investigated, the Ru/ZSM-5-TF catalysts were observed to function more effectively and selectively when producing D-sorbitol, giving markedly higher yields of D-sorbitol compared with other catalysts such as Ru/ZSM-5-MS and $\mathrm{Ru} / \mathrm{ZSM}-5-\mathrm{AT}$. However, the sorbitol selectivity was only $61.7 \%$ on $\mathrm{Ru} / \mathrm{C}$, and this relatively low catalytic activity may be due to the lower dispersion of $\mathrm{Ru}$ on $\mathrm{Ru} / \mathrm{C}$ in comparison with that on ZSM-5-TF. Based on the above analysis, ZSM-5-TF was the best support for the Ru catalyst in the selective hydrogenation of D-glucose to D-sorbitol.

As shown by the TEM images, the template-free fabrication produces highly dispersed and isolated $\mathrm{Ru}$ species within $\mathrm{Ru} / \mathrm{ZSM}-5-\mathrm{TF}$. The small clusters were uniform in size and homogeneously distributed throughout the zeolite materials, as shown in Fig. 4. Both Ru/ZSM-5-MS and Ru/ZSM-5-AT, however, exhibited aggregated $\mathrm{Ru}$ nanoparticles with larger particle sizes in the zeolite nanocrystals. This suggested that the template-free method represents a very promising route to overcome problems with particle aggregation and also that highly

Table 2

Catalytic performances of Ru-based heterogeneous catalysts in the hydrogenation reaction of D-glucose.

\begin{tabular}{|c|c|c|c|c|}
\hline Catalysts & $\begin{array}{c}\text { Temperature } \\
\left({ }^{\circ} \mathrm{C}\right)\end{array}$ & $\begin{array}{c}\text { Conversion } \\
(\%)\end{array}$ & $\begin{array}{c}\text { D-sorbitol yield } \\
(\%)\end{array}$ & $\begin{array}{l}\text { TOF } \\
\left(h^{-1}\right)\end{array}$ \\
\hline ZSM-5 & 120 & 30.2 & 1.2 & 2 \\
\hline $\mathrm{Ru} / \mathrm{C}^{\mathrm{a}}$ & 120 & 81.3 & 61.7 & 13 \\
\hline $\mathrm{Ru} / \mathrm{ZSM}-5-\mathrm{MS}$ & 120 & 98.4 & 95.8 & 15 \\
\hline $\mathrm{Ru} / \mathrm{ZSM}-5-\mathrm{AT}$ & 120 & 98.8 & 97.4 & 18 \\
\hline $\mathrm{Ru} / \mathrm{ZSM}-5-\mathrm{TF}$ & 70 & 62.3 & 41.8 & 7 \\
\hline $\mathrm{Ru} / \mathrm{ZSM}-5-\mathrm{TF}$ & 80 & 66.6 & 56.9 & 10 \\
\hline Ru/ZSM-5-TF & 90 & 65.3 & 63.2 & 19 \\
\hline $\mathrm{Ru} / \mathrm{ZSM}-5-\mathrm{TF}$ & 100 & 69.6 & 68.2 & 21 \\
\hline $\mathrm{Ru} / \mathrm{ZSM}-5-\mathrm{TF}$ & 110 & 98.3 & 97.2 & 29 \\
\hline $\mathrm{Ru} / \mathrm{ZSM}-5-\mathrm{TF}$ & 120 & 99.6 & 99.2 & 32 \\
\hline $\mathrm{Ru} / \mathrm{ZSM}-5-\mathrm{TF}$ & 130 & 97.5 & 97.0 & 30 \\
\hline
\end{tabular}

Reaction conditions: $4.0 \mathrm{MPa} \mathrm{H}_{2}$, catalyst $0.5 \mathrm{~g}, 25 \mathrm{wt} \%$ D-glucose aqueous solution $50 \mathrm{~g}, 2 \mathrm{~h}$. Sorbitol reaction activity is reported as molar sorbitol conversion rate per mole of metal per hour $\left(\mathrm{h}^{-1}\right)$.

a The dispersion measured by hydrogen chemisorption for $\mathrm{Ru} / \mathrm{C}$ was 0.23 . dispersed $\mathrm{Ru}$ centers result in much higher activity for D-glucose hydrogenation than larger Ru particles.

The observed high performance of the Ru/ZSM-5 catalyst can be explained in terms of bifunctional catalysis, since this system possesses both acidic (the support) and basic (the metal) sites on the surface. The saccharide molecule adsorbs on the acidic sites of ZSM-5 through its $\mathrm{C}=0$ bond, which can work in tandem with the dissociative adsorption of hydrogen at the basic sites. As indicated by the $\mathrm{NH}_{3}$-TPD test (Fig. 3(a)), the performances of the supported Ru catalysts under the investigated conditions was not directly linked to their apparent acidity. Therefore, the basicities of different $\mathrm{Ru} / \mathrm{ZSM}-5$ samples were measured by the $\mathrm{CO}_{2}$-TPD method. As can be seen from Fig. 3(b), two peaks were observed in all samples, one of which was positioned at about $227^{\circ} \mathrm{C}$ and the other at approximately $477{ }^{\circ} \mathrm{C}$. In the case of $\mathrm{Ru} / \mathrm{ZSM}-5-\mathrm{AT}$ and $\mathrm{Ru} / \mathrm{ZSM}-5-\mathrm{MS}$, both peaks were shifted to lower temperatures, indicating a decrease in the strength of the basic sites, which could lead to less hydrogen dissociative production at these sites [31]. These results indicated that the basic sites on Ru centers seemed to be critical for the activity and selectivity of the Ru/ZSM-5 catalysts.

Based on the above discussion, we conclude that it is possible to increase the activity and selectivity of the catalysts during D-glucose hydrogenation through modifications of the structure, $\mathrm{Ru}$ dispersity and acid-base properties of the $\mathrm{Ru} / Z S M-5$. The mesopore structure of Ru/ZSM-5-AT produced by desilication in $\mathrm{NaOH}$ led to no significant improvement in product yields. Interestingly, the Ru/ZSM-5-TF synthesized using a template-free method represents a potentially suitable candidate for D-glucose hydrogenation catalytic applications.

\subsection{Effect of reaction temperature on the conversion of D-glucose and the selectivity for D-sorbitol}

The effects of reaction temperature on the hydrogenation were also examined, with Ru-ZSM-5-TF as the catalyst (Table 2) in the range from 70 to $130{ }^{\circ} \mathrm{C}$. Hydrogenation of D-glucose was found to be quite temperature sensitive, such that high reaction temperatures improved both the D-glucose conversion and the D-sorbitol selectivity. It can be seen that the conversion of D-glucose increased continuously, from $62.3 \%$ to $99.6 \%$, while the yield of D-sorbitol increased from $21.8 \%$ to $99.2 \%$ as the temperature was increased from 70 to $120{ }^{\circ} \mathrm{C}$. However, when the temperature was elevated to $130{ }^{\circ} \mathrm{C}$, the selectivity for D-sorbitol decreased to $97.0 \%$, possibly due to the formation of by-products such as D-fructose. D-fructose could also be subsequently hydrogenated into D-sorbitol, D-mannitol, D-mannose and other degradation products [16,32]. These results demonstrated that the optimal reaction temperature for the D-glucose hydrogenation was $120^{\circ} \mathrm{C}$, since higher temperature may promote competitive side-reactions and speed up the loss of active components.

\subsection{The effect of Ru loading in the catalyst}

To maximize the catalytic activity of the Ru catalyst, the ef- 
fect of metal loading was investigated over medium-pore, Ru-containing ZSM-5 catalysts during the hydrogenation reaction of D-glucose. It can be observed from Fig. 5 that the mean catalytic activity increased with increasing Ru loading up to 4.1 $\mathrm{wt} \%$, and then slightly decreased with further addition of $\mathrm{Ru}$. More importantly, the formation of undesirable by-products, i.e. D-fructose and D-mannitol, was significantly minimized with increasing metal loading. For example, D-glucose conversion below $61.8 \%$ and $15.9 \%$ D-sorbitol selectivity were obtained when the content of Ru was $1.2 \mathrm{wt} \%$ at $120{ }^{\circ} \mathrm{C}$. By increasing the $\mathrm{Ru}$ loading to $4.1 \mathrm{wt} \%$, the D-glucose conversion and the D-sorbitol selectivity were improved to $99.6 \%$ and $99.2 \%$, respectively.

It should be noted that the dispersion of $\mathrm{Ru}$ on the $\mathrm{Ru} / Z \mathrm{SM}-5-\mathrm{TF}$ catalysts was slightly changed and the mean crystallite size of $\mathrm{Ru}$ varied between 0.5 and $0.9 \mathrm{~nm}$ when increasing the metal loading from 1.0 to $4.1 \mathrm{wt} \%$, as shown in Fig. 4. Also, particles over $1 \mathrm{~nm}$ in size were seen at a Ru loading of $5 \mathrm{wt} \%$, indicating that large nanoparticle clusters were formed predominantly on the external surfaces of ZSM-5 materials when the Ru loading was increased up to $5 \mathrm{wt} \%$. Accordingly, the interaction of Ru with the support was weakened, accompanied by a decline in the hydrogenation activity. Therefore, $\mathrm{Ru}$ levels below $4.1 \mathrm{wt} \%$ are beneficial with regard to the hydrogenation activity, as a result of the good dispersion of Ru nanoparticles and the increased number of active sites.

\subsection{The recyclability of catalysts}

Recycling of the Ru/ZSM-5-TF catalyst was also investigated during the hydrogenation of D-glucose. It was found that the entire system could be reused successively for five trials under the same reaction conditions without the requirement to add any additional catalyst. After each reaction run, the $\mathrm{Ru} / \mathrm{ZSM}-5$ was recycled, dried at $120{ }^{\circ} \mathrm{C}$ in air and regenerated without further treatment. During this series of trials, the reaction con-

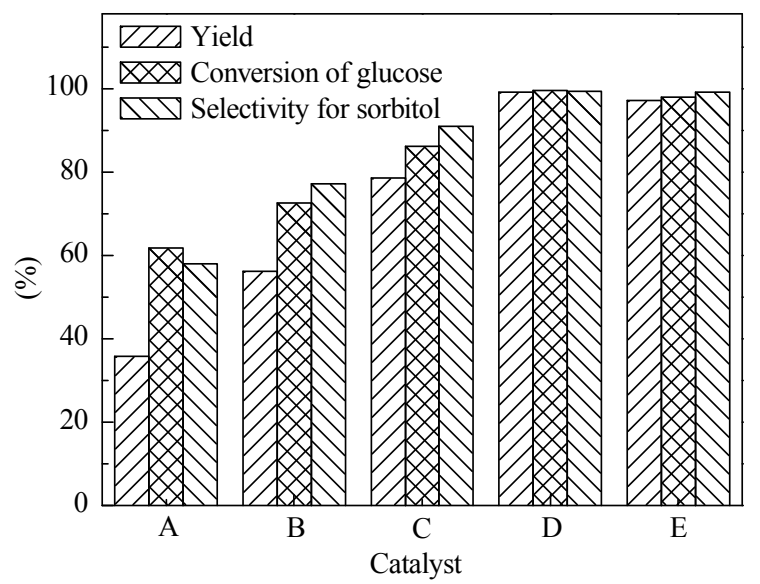

Fig. 5. Conversion of D-glucose, yield and selectivity for D-sorbitol over 1.2Ru/ZSM-5-TF (A), 2.3Ru/ZSM-5-TF (B), 2.9Ru/ZSM-5-TF (C), 4.1Ru/ZSM-5-TF (D) and 5.2Ru/ZSM-5-TF (E) catalysts. (The numbers at the beginning of the sample designation give the ruthenium content of the dry zeolite in wt.\%. Reaction conditions: $200{ }^{\circ} \mathrm{C}, 4.0 \mathrm{MPa} \mathrm{H}_{2}$, catalyst $0.5 \mathrm{~g}$, $25 \mathrm{wt} \%$ D-glucose aqueous solution $50 \mathrm{~g}$.)

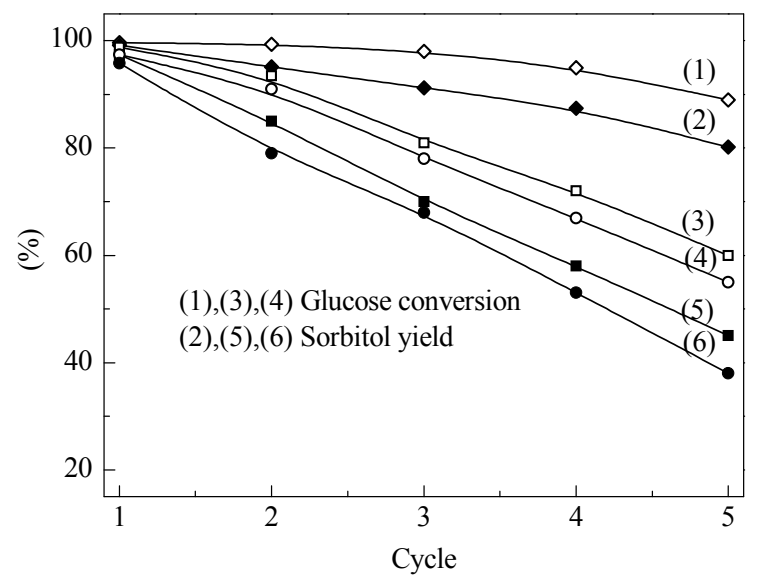

Fig. 6. Stability of Ru/ZSM-5-TF $(1,2)$, Ru/ZSM-5-AT $(3,5)$, and $\mathrm{Ru} / Z S M-5-M S(4,6)$ upon catalyst recycling. Reaction conditions: 220 ${ }^{\circ} \mathrm{C}, 4.0 \mathrm{MPa} \mathrm{H}$, Ru/ZSM-5 $0.5 \mathrm{~g}, 25$ wt $\%$ D-glucose aqueous solution 50 g, 2 h.

ditions were held constant. As observed in Fig. 6, Ru/ZSM-5-TF clearly showed higher glucose conversion and sorbitol selectivity during all the runs compared with the Ru/ZSM-5-AT and $\mathrm{Ru} / \mathrm{ZSM}-5$-MS catalysts and could be reused with little loss of catalytic activity and selectivity after five recycling trials. This is also supported by the observation that the reaction liquid remained colorless after filtration of the catalyst and that almost no leaching of Ru particles was detected by ICP after five runs. Moreover, no aggregation of $\mathrm{Ru}$ nanoparticles was detected from the TEM images (Fig. 7(a)). The decrease in glucose conversion from $99.7 \%$ to $89.2 \%$ after the fifth run is due to the regeneration method employed. When $\mathrm{Ru} / \mathrm{ZSM}-5-\mathrm{TF}$ was only dried at $120^{\circ} \mathrm{C}$ in air, and reused without further treatment, the sorbitol yield decreased to $89.2 \%$ after five runs. However, when the spent catalyst was washed with water and subsequently washed with ethanol or acetone three times each, there was no obvious loss of the catalytic reactivity. The deactivation therefore may be caused by the accumulation of organic and inorganic species adsorbed on the surface of the catalyst. These results clearly showed that $\mathrm{Ru} / \mathrm{ZSM}-5-\mathrm{TF}$ was effective for the hydrogenation of D-glucose and had good stability during the reaction process.

In contrast, the D-sorbitol yields over Ru/ZSM-5-MS and $\mathrm{Ru} / Z \mathrm{ZM}-5-\mathrm{AT}$ dropped to $45 \%$ and $38 \%$ by the fifth use, respectively. The observed quick deactivation of these catalysts could be attributed to the weak interactions between ruthenium and the supports, which enabled particle aggregation/sintering and leaching during use [20]. The levels of leached ruthenium in the reaction solutions, as determined by ICP-OES, were 0.53-0.61 ppm when Ru/ZSM-5-MS or $\mathrm{Ru} / \mathrm{ZSM}-5-\mathrm{AT}$ were used as catalysts. In addition, it is challenging to precisely control the size and location of the metal particles on the solid support through conventional impregnation approaches (Fig. 7(b) and (c)). In summary, the medium-pore $\mathrm{Ru} / \mathrm{ZSM}-5$ prepared by the one-step method has been shown to be an efficient catalyst for hydrogenation of D-glucose, as a result of the improved zeolite structure and good dispersion of the metallic Ru throughout the ZSM-5. 


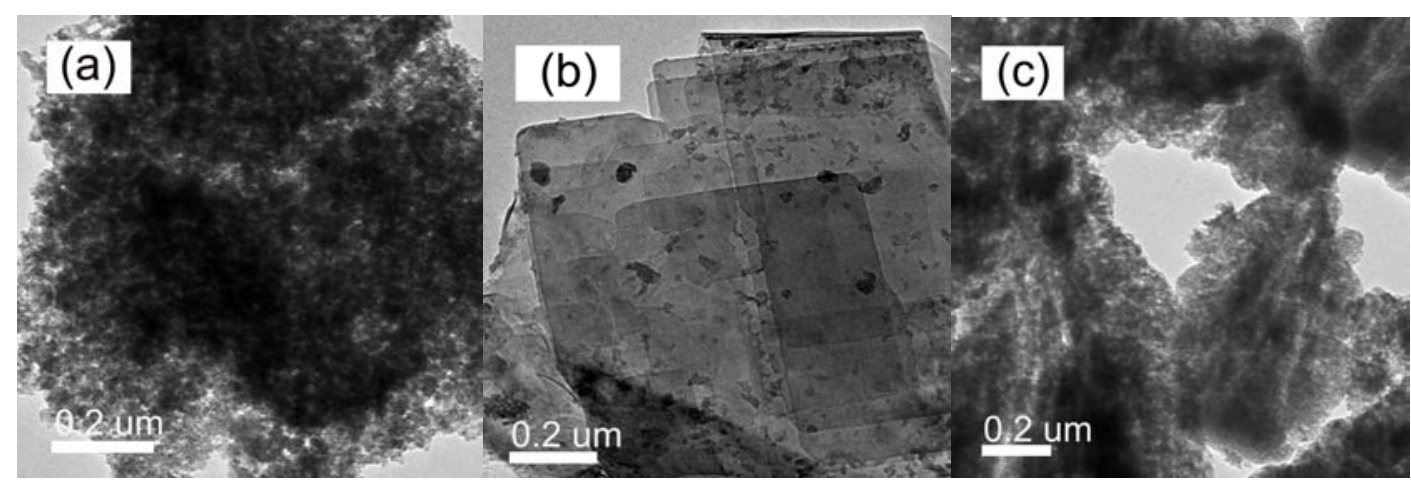

Fig. 7. TEM images of the Ru-containing ZSM-5 samples after reuse. (a) Ru/ZSM-5-TF; (b) Ru/ZSM-5-AT; (c) Ru/ZSM-5-MS.

\section{Conclusions}

$\mathrm{Ru} / \mathrm{ZSM}-5-\mathrm{TF}$ were successfully synthesized from a template-free gel using a hydrothermal ZSM-5 method. The $\mathrm{Ru}$ species in the zeolite prepared were too small to be detected by XRD, indicating the presence of Ru clusters with sizes of $1 \mathrm{~nm}$ or less. Ru/ZSM-5-TF was highly active and selective during the hydrogenation of D-glucose to D-sorbitol and over 99\% conversion of D-glucose and selectivity for D-sorbitol were achieved. The preparation method had significant effects on the catalytic performance as a result of influencing the structure of the support and/or the electronic state and particle size of the ruthenium. Ru/ZSM-5-TF showed higher activity and selectivity than $\mathrm{Ru} / Z S M-5-M S$ and Ru/ZSM-5-AT. In addition, Ru/ZSM-5-TF was a more stable heterogeneous catalyst and could be recycled with simple regeneration.

\section{References}

[1] Liu J, Tian X N, Zhao X S. Aust J Chem, 2009, 62: 1020

[2] Perrard A, Gallezot P, Joly J P, Durand R, Baljou C, Coq B, Trens P. Appl Catal A, 2007, 331: 100

[3] Kubička D, Kubičková I, Čejka J. Catal Rev Sci Eng, 2013, 55: 1

[4] Gallezot P. Chem Soc Rev, 2012, 41: 1538
[5] Li H, Li H, Wang M. Appl Catal A, 2001, 207: 129

[6] Eisenbeis C, Guettel R, Kunz U, Turek T. Catal Today, 2009, 147: S342

[7] Liu J, Bai P, Zhao X S. Phys Chem Chem Phys, 2011, 13: 3758

[8] Gallezot P. Catal Today, 2007, 121: 76

[9] Hoffer B W, Crezee E, Mooijman P R M, van Langeveld A D, Kapteijn F, Moulijn J A. Catal Today, 2003, 79-80: 35

[10] Maris E P, Ketchie W C, Oleshko V, Davis R J.J Phys Chem B, 2006, 110: 7869

[11] Zhang J, Lin L, Zhang J, Shi J. Carbohydr Res, 2011, 346: 1327

[12] Pan J, Li J, Wang C, Yang Z. React Kinet Catal Lett, 2007, 90: 233

[13] Crezee E, Hoffer B W, Berger R J, Makkee M, Kapteijn F, Moulijn J A. Appl Catal A, 2003, 251: 1

[14] Luo C, Wang S, Liu H. Angew Chem Int Ed, 2007, 46: 7636

[15] Arena B J. Appl Catal A, 1992, 87: 219

[16] Kusserow B, Schimpf S, Claus P. Adv Synth Catal, 2003, 345: 289

[17] Zhang J, Wu S, Liu Y, Li B. Catal Commun, 2013, 35: 23

[18] Jae J, Tompsett G A, Foster A J, Hammond K D, Auerbach S M, Lobo R F, Huber G W. J Catal, 2011, 279: 257

[19] Parlett C M A, Wilson K, Lee A F. Chem Soc Rev, 2013, 42: 3876

[20] Scholz K, Scholz J, James McQuillan A, Wagner G, Klepel O. Carbon, 2010, 48: 1788

[21] Sun J, Bao X. Chem Eur J, 2008, 14: 7478

[22] Song W, Justice R E, Jones C A, Grassian V H, Larsen S C. Langmuir, 2004, 20: 8301

[23] Zhan B Z, Iglesia E. Angew Chem Int Ed, 2007, 46: 3697

[24] Altwasser S, Gläser R, Weitkamp J. Microporous Mesoporous Mater,

\section{Graphical Abstract}

Chin. J. Catal., 2014, 35: 733-740 doi: 10.1016/S1872-2067(14)60077-2

\section{Selective hydrogenation of D-glucose to D-sorbitol over $\mathrm{Ru} / \mathrm{ZSM}-5$ catalysts}

Xingcui Guo, Xicheng Wang, Jing Guan, Xiufang Chen, Zhangfeng Qin, Xindong Mu*, Mo Xian Qingdao Institute of Bioenergy and Bioprocess Technology, Chinese Academy of Science; Institute of Coal Chemistry, Chinese Academy of Sciences

D-glucose was selectively converted into D-sorbitol with a yield of $99.2 \%$ over a $\mathrm{Ru} / \mathrm{ZSM}-5-\mathrm{TF}$ catalyst synthesized via a template-free hydrothermal method. This catalyst could be recycled via a simple regeneration process.

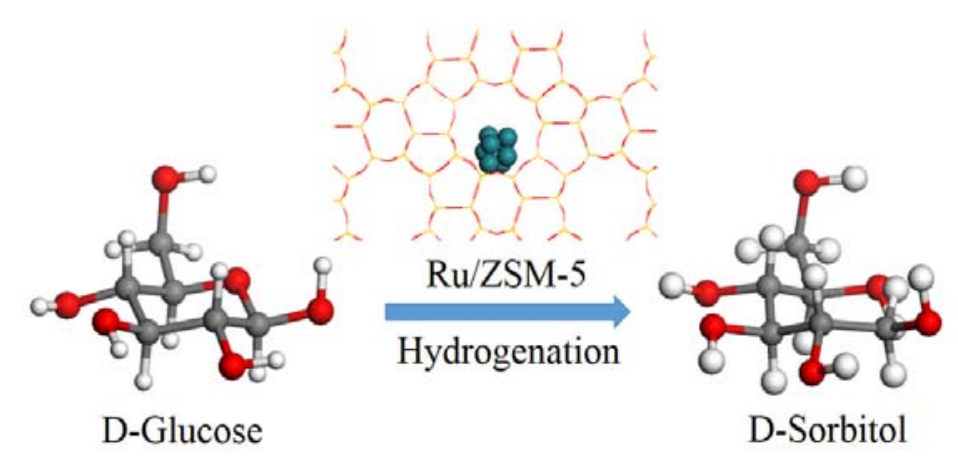


2007, 104: 281

[25] Zhan B Z, White M A, Sham T K, Pincock J A, Doucet R J, Rao K V R, Robertson K N, Cameron T S. J Am Chem Soc, 2003, 125: 2195

[26] Altwasser S, Gläser R, Lo A S, Liu P H, Chao K J, Weitkamp J. Microporous Mesoporous Mater, 2006, 89: 109

[27] Melian-Cabrera I, Espinosa S, Groen J C, Linden B, Kapteijn F, Moulijn J A. J Catal, 2006, 238: 250

[28] Mishra D K, Lee J M, Chang J S, Hwang J S. Catal Today, 2012, 185: 104
[29] Yoo W C, Zhang X, Tsapatsis M, Stein A. Microporous Mesoporous Mater, 2012, 149: 147

[30] Groen J C, Peffer L A A, Moulijn J A, Pérez-Ramırez J. Microporous Mesoporous Mater, 2004, 69: 29

[31] Martins Castoldi M C, Câmara L D, Monteiro R S, Constantino A M, Camacho L, Carneiro J W M, Aranda D A G. React Kinet Catal Lett, 2007, 91: 341

[32] Sifontes Herrera V A, Oladele O, Kordás K, Eränen K, Mikkola J P, Murzin D Y, Salmi T.J Chem Technol Biotechnol, 2011, 86: 658

\section{Ru/ZSM-5催化葡萄糖选择性加氢制备山梨醇}

郭星翠 ${ }^{\mathrm{a}}$, 王喜成 $\mathrm{a}$, 关 静 ${ }^{\mathrm{a}}$ ，陈秀芳 ${ }^{\mathrm{a}}$, 秦张峰 ${ }^{\mathrm{b}}$ ，牟新东 ${ }^{\mathrm{a}}{ }^{*}$, 咸 漠 $^{\mathrm{a}}$

a 中国科学院青岛生物能源与过程研究所, 中国科学院生物基材料重点实验室, 山东青岛 266101

b 中国科学院山西煤炭化学研究所, 煤转化国家重点实验室, 山西太原030001

摘要: 采用无有机模板剂一步法制备了 Ru/ZSM-5催化剂, 利用X射线衍射、 $\mathrm{N}_{2}$ 吸附-脱附、 $\mathrm{NH}_{3}$-程序升温脱附和 $\mathrm{CO}_{2}$-程序升温脱 附、扫描电镜和透射电镜等方法对催化剂进行了表征. 考察了反应温度、钓负载量和催化剂重复利用等因素对Ru/ZSM- 5 上葡萄 糖加氢反应性能的影响, 并与浸渍法制备的Ru/ZSM-5催化剂进行了对比. 结果表明, 与传统浸渍法相比, 一步法制备的Ru/ZSM-5 催化剂钓粒子具有更高的分散性和稳定性. 在 $120^{\circ} \mathrm{C}$ 和 $4 \mathrm{MPa}$ 的温和反应条件下, 葡萄糖接近完全转化, 山梨醇选择性高达 $99.2 \%$, 催化剂可重复利用5次, 仍保持较高活性.

关键词: 加氢; 葡萄糖; 山梨醇; 钉; ZSM-5

收稿日期: 2014-01-20. 接受日期: 2014-03-13. 出版日期: 2014-05-20.

*通讯联系人. 电话: (0532)80662723; 传真: (0532)80662724; 电子信箱: muxd@qibebt.ac.cn

基金来源：国家自然科学基金(21273260，21303238，21201174); 山东省自然科学杰出青年基金(JQ201305); 煤转化国家重点实验 室开放基金(J13-14-603).

本文的英文电子版由Elsevier出版社在ScienceDirect上出版(http://www.sciencedirect.com/science/journal/18722067). 